\title{
PARTITIONING OF LIPID IN THE BODY OF FAT-TAILED LAMBS AS INFLUENCED BY DOCKING AND SEX
}

\author{
M. A. Abouheif', M. S. Kraidees and R. A. Shatat \\ Animal Production Department, College of Agriculture \\ King Saud University, Riyadh 11451, Saudi Arabia
}

\begin{abstract}
Summary
Twelve docked and 12 intact Najdi lambs of equal numbers of males and females were slaughtered at $40 \mathrm{~kg}$ shorn shrunk body weight, Lipid in all empty body fat components; namely, subcutaneous, intermuscular, intramuscular, omental, mesentric, channel, perirenal, pericardial, tail, viscera, bone and hide, were determined. Except for ram lambs, which had a lower percentage of lipid in intermuscular partition in loin cut, sex did not influence the relative proportion of subcutaneous or intermuscular fat in each wholesale cut. The data also showed that docking did not change the distribution of lipid in intermuscular and intramuscular fat partitions in each wholesale cut. Docked lambs tended to accumulate lower proportions of the lipid in subcutaneous fat component in the cuts located along the dorsal line than intact lambs. The total amount of lipid deposited in the empty body of ewe lamb was heavier in weight than that of ram lamb. Docking had no effect on the distribution of total lipid in the empty body, except for subcutaneous fat component, being greater in docked lambs than did intact ones. Generally, the highest proportion of fat was associated with subcutaneous depot followed, in order, by intermuscular, mesentric, tail, intramuscular and omental fat partitions.
\end{abstract}

(Key Words : Docking, Fat-tailed Lambs, Najdi Lambs, Fat Partitioning)

\section{Introduction}

Fat is a body reserve and differences in fat amount and partition are important when defining selection objectives, studying stress susceptibility, metabolic efficiency and meat quality (Kempster, 1981). These differences are major determinants of the value of the carcass through their influence or lack of influence on these determinants. Factors such as breed, sex and nutritional history could then alter the value of a carcass. Thompson et al. (1979a) and Field et al. (1985) found that partitioning of total dissectible fat between subcutaneous and intermuscular fat depots was not affected by breed of sheep. Also, Theriez et al. (1981) and Leymaster and Jenkins (1985) found no effect of intake level on fatness among growing lambs slaughtered at constant weight. Abouheif et al. (1992) showed a significant effect

\footnotetext{
${ }^{1}$ Address reprint requests to Dr. M. A. Abouheif Department of Animal Production, College of Agriculture, King Saud University, P. O. Box. 2460, Riyadh 11451, Saudi Arabia.

Received March 6, 1992

Accepted October 27, 1992
}

of docking on carcass fatness among fat-tailed lambs. It is assumed that docking would improve the efficiency of growth by eliminating the deposition of fat in the tail. However, information is not available concerning the effect of docking on the redistribution of fat in the whole body of fat-tailed lambs. This study was intended to investigate the effect of docking on the distribution of lipid among various fat partitions in the body and wholesale cuts of male and female Najdi lambs slaughtered at $40 \mathrm{~kg}$ shorn shrunk body weight.

\section{Materials and Methods}

Twenty four single Najdi lambs of equal numbers of male and female were used in the experiment. Of those lambs, twelve $(6$ males and 6 females) were docked before they were three days of age using the rubber ring elastrator. All lambs were raised under similar environmental, nutritional and management conditions. Lambs had access to alfalfa hay and a creep feed (18\% $\mathrm{cp}$ and $12.54 \mathrm{MJ} \mathrm{ME} / \mathrm{kg}$ ) until they were weaned at eight weeks of age. After weaning, lambs were fed ad libitum on a diet formulated to contain 
11.4 MJ ME/kg and consisted of $50 \%$ alfalfa hay and $50 \%$ commercial concentrate. Body weight of each lamb was recorded every two weeks until they attained $40 \mathrm{~kg}$ and then once every week.

When each lamb attained approximately 43 $\mathrm{kg}$ live weight, the fleece was sheared and the body weight was recorded after 18-hr period without feed (shorn shrunk slaughter weight). At slaughter, draining blood was collected and weighed; perirenal, channel, pericardial, omental and mesentric fatty tissues were removed, weighed and individually sampled, and gastrointestinal tracts were emptied and washed. Any fat still adherent to the skin was removed and bulked with the subcutaneous fat dissected from the corresponding wholesale cut of the lamb. The skin also was sampled at the mid-side area of the body, minced and saved. Head and feet (metatarsal and metacarpal) were broken and scraped clean of all soft tissues; thereafter, the bones were crushed, sampled and referred to noncarcass bone. All internal organs (which included liver kidneys, heart, lungs, spleen, sex organs, diaphragm, gastrointestinal tracts and trachea) plus the soft tissues scraped from head and feet were pooled into a single weight referred to viscera; the viscera was minced and sampled.

The carcass was split longitudinally into halves, and the right side was fabricated into six wholesale cuts as described by Romans et al. (1985). Each cut was then dissected into subcutaneous fat, intermuscular fat, lean and bone; each of the component was weighed, minced and sampled. Generally, great care was taken to get adequate mincing and mixing before sampling the tissues. All samples were stored forzen at $-20^{\circ} \mathrm{C}$ until they were analyzed in duplicate for lipid (ether extractable material) using the procedures outlined by Little and Sandland (1975). However, blood was not analyzed and assumed to contain negligible amounts of fat (Russel et al., 1971). Subcutaneous fat, intermuscular fat, intramuscular fat in the carcass and carcass fat in the bone depot were estimated as described by Abouheif et al. (1988).

Lipid weight in each fat component was analyzed statistically by GLM, fixed-model procedures (SAS, 1986). The independent variables in the model included main effects of sex, docking treatment and their two-way interactions. Shorn shrunk slaughter weight was included in the model as a covariat. This model approximates results that would be obtained if each lamb had been slaughtered at the same average shorn shrunk weight of $40.06 \mathrm{~kg}$. Treatment means were separated by Duncan's multiple range test. In this experiment, all significant interactions were caused by a change in magnitude not a change in rank, thus we only considered the main effects. The values obtained in percentages were transformed by arcsin transformation in order to meet the requirement of normal distribution. Thereafter, statistical analysis and testing the effect of sex and docking on the percentage of fat were examined.

\section{Results and Discussion}

Least square means for the effect of sex and docking treatment on the distribution of lipid weight in subcutaneous fat partition in wholesale cuts are listed in table 1. Means were adjusted to a constant shorn shrunk body weight $(40 \mathrm{~kg})$ to minimize differences among slaughter groups. The adjusted means were also converted into percentages of total lipid in subcutaneous fat component and presented in table 1. There was no sex effect on the lipid weight in subcutaneous fat component produced from each studied wholesale cut. At similar slaughter weight, the distribution of total carcass subcutaneous fat in the wholesale cuts was remarkably uniform in ram and ewe lambs, which corroborates previous findings (Thompson et al., 1979b). Only lipid weight in subcutaneous fat component from flank and leg cuts were greater $(p<.05)$ in docked lambs than in intact ones. Lipid weight in subcutaneous fat component in leg cut also was a greater percentage $(p<.05)$ in docked lambs, and shoulder, rack and loin cuts were lower percentages $(p<.05)$, of the total lipid weight in subcutaneous fat component. This indicates that docking had an effect on subcutaneous fat distribution within the carcass. Docked lambs tended to accumulate a lower proportion of subcutaneous fat in the cuts located along the dorsal line than in intact lambs. Also, the greater lipid weight in subcutaneous fat component in leg cut may explain the increases in buttock size in docked lambs (Abouheif et al., 1992).

Generally, the leg cut had the highest proportion of the subcutaneous fat, followed by 
TABLE 1. LEAST-SQUARE MEANS, STANDARD ERRORS (SE), INTERACTIONS AND RELATIVE PROPORTIONS (\%) OF LIPID WEIGHT IN SUBCUTANEOUS FAT COMPONENT IN WHOLESALE CUTS FROM NAJDI LAMBS ADJUSTED TO $40 \mathrm{KG}$ SHORN SHRUNK WEIGHT

\begin{tabular}{|c|c|c|c|c|c|c|}
\hline \multirow{2}{*}{ Effect } & \multicolumn{6}{|c|}{ Wholesale cut } \\
\hline & Breast & Shoulder & Rack & Loin & Flank & Leg. \\
\hline \multicolumn{7}{|c|}{ 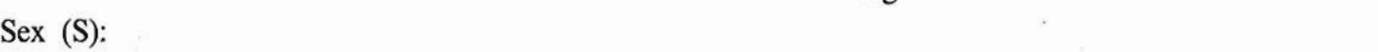 } \\
\hline Ram & .574 & .233 & .285 & .446 & .326 & 1.112 \\
\hline Ewe & .579 & .221 & .304 & .506 & .328 & 1.035 \\
\hline \multicolumn{7}{|l|}{ Treatment $(\mathrm{T})$ : } \\
\hline Docked & .644 & .232 & .306 & .495 & $.384^{\mathrm{a}}$ & $1.390^{\mathrm{a}}$ \\
\hline Intact & .509 & .222 & .282 & .458 & $.270^{\mathrm{b}}$ & $.756^{\mathrm{b}}$ \\
\hline SE & .07 & .03 & .02 & .04 & .03 & .06 \\
\hline Interaction $(\mathrm{S} \times \mathrm{T})$ & NS & NS & NS & NS & $\mathrm{p}<.05$ & $\mathrm{p}<.05$ \\
\hline & \multicolumn{6}{|c|}{ (n) } \\
\hline \multicolumn{7}{|c|}{ 为 } \\
\hline Ram & 19.3 & 7.8 & 9.6 & 15.0 & 10.9 & 37.4 \\
\hline Ewe & 19.5 & 7.5 & 10.2 & 17.0 & 11.0 & 34.8 \\
\hline \multicolumn{7}{|l|}{ Treatment: } \\
\hline Docked & 18.7 & $6.7^{\mathrm{b}}$ & $8.9^{\mathrm{b}}$ & $14.3^{\mathrm{b}}$ & 11.1 & $40.3^{\mathrm{a}}$ \\
\hline Intact & 20.4 & $8.9^{\mathrm{a}}$ & $11.3^{\mathrm{a}}$ & $18.3^{\mathrm{a}}$ & 10.8 & $30.3^{\mathrm{b}}$ \\
\hline
\end{tabular}

a,b Values in the same column, within an effect, bearing different superscripts are different $(p<.05)$.

breast, loin, flank, rack and shoulder cuts. These results, however, are in general agreement with those reported by Kempster et al. (1976) who found that subcutaneous fat was more concentrated in the joints of the hindquarter with $24 \%$ of the depot weight in the top piece.

Least square means for the lipid weight in the intermuscular fat partition and their relative proportions in various wholesale cuts as affected by sex and docking treatment are presented in table 2. The lipid weight in the intermuscular fat component in each wholesale cut and the distribution of total intermuscular fat in the cuts were very consistent among sex and docking treatment subclasses. Ram lamb carcass was associated with lower $(\mathrm{p}<.05)$ proportion of lipid in intermuscular fat component in the loin cut than in ewe lamb carcass. Gaili (1978) and Thompson et al. (1979b) found that the distribution of intermuscular fat in the various joints of the lamb carcasses were not affected by sex. The highest amount or proportion of lipid in intermuscular fat component was distributed in breast cut followed by shoulder cut, these cuts together accounting for nearly $55 \%$ of the total depot weight. Similar results were reported in steers by Kempster et al. (1976) who found that $40 \%$ of the total intermuscular fat were deposited in the coast and pony joints (comparable partly to breast and shoulder cuts).

Least square means for the effect of sex and docking on the lipid weight in the intramuscular fat component and their relative proportions in wholesale cuts are listed in table 3. Only lipid weight in intramuscular fat component from loin cut was heavier $(\mathrm{p}<.05)$ in ewe lamb carcasses than in ram lamb carcasses. Also, intramuscular fat in leg cut was a greater $(p<.05)$ percentage in ewe lamb carcasses, and shoulder was lower percentage $(p<.05)$ of the total lipid weight in intramuscular fat component. The lipid weight in intramuscular fat component and its distribution in various wholesale cuts was not affected by docking treatment of lambs. Generally, the highest amount and proportion of lipid in intramuscular fat component was found in leg cut followed, in order, by shoulder, breast, rack, loin and flank wholesale cuts. It seems that the ranking order of intramuscular fat distribution in lamb carcasses is a weight dependent; the heavier 
TABLE 2. LEAST-SQUARE MEANS, STANDARD ERRORS (SE), INTERACTIONS AND RELATIVE PROPORTIONS (\%) OF LIPID WEIGHT IN INTERMUSCULAR FAT COMPONENT IN WHOLESALE CUTS FROM NAJDI LAMBS ADJUSTED TO $40 \mathrm{KG}$ SHORN SHRUNK WEIGHT

\begin{tabular}{|c|c|c|c|c|c|c|}
\hline \multirow{2}{*}{ Effect } & \multicolumn{6}{|c|}{ Wholesale cut } \\
\hline & Breast & Shoulder & Rack & Loin & Flank & Leg \\
\hline & ..... & ……... & …..... & (n......... & …...... & ....... \\
\hline \multicolumn{7}{|l|}{ Sex (S): } \\
\hline Ram & .563 & .471 & .174 & $.162^{b}$ & .134 & .387 \\
\hline Ewe & 649 & .559 & .173 & $.254^{\mathrm{a}}$ & .149 & .401 \\
\hline \multicolumn{7}{|l|}{ Treatment $(\mathrm{T})$ : } \\
\hline Docked & .581 & .536 & .182 & .218 & .149 & .370 \\
\hline Intact & .630 & .494 & .165 & .198 & .134 & .417 \\
\hline SE & .04 & .03 & .01 & .02 & .02 & .02 \\
\hline Interaction $(\mathrm{S} \times \mathrm{T})$ & NS & NS & NS & $\mathrm{p}<.05$ & NS & $\mathrm{p}<.05$ \\
\hline & $\cdots \cdot$ & ........... & ........ & $\cdots \cdots$ & $\cdots \cdots$ & $\cdots$ \\
\hline \multicolumn{7}{|l|}{ Sex: } \\
\hline Ram & 29.8 & 24.9 & 9.1 & $8.6^{\mathrm{b}}$ & 7.1 & 20.5 \\
\hline Ewe & 29.7 & 25.6 & 7.9 & $11.6^{\mathrm{a}}$ & 6.8 & 18.4 \\
\hline \multicolumn{7}{|l|}{ Treatment: } \\
\hline Docked & 28.6 & 26.3 & 8.9 & 10.7 & 7.3 & 18.2 \\
\hline Intact & 30.9 & 24.2 & 8.1 & 9.7 & 6.6 & 20.5 \\
\hline
\end{tabular}

a,b Values in the same column, within an effect, bearing different superscripts are different $(p<.05)$.

TABLE 3. LEAST-SQUARE MEANS, STANDARD ERRORS (SE), INTERACTIONS AND RELATIVE PROPORTIONS (\%) OF LIPID WEIGHT IN INTRAMUSCULAR FAT COMPONENT IN WHOLESALE CUTS FROM NAJDI LAMBS ADJUSTED TO $40 \mathrm{KG}$ SHORN SHRUNK WEIGHT

\begin{tabular}{|c|c|c|c|c|c|c|}
\hline \multirow{2}{*}{ Effect } & \multicolumn{6}{|c|}{ Wholesale cut } \\
\hline & Breast & Shoulder & Rack & Loin & Flank & Leg \\
\hline \multicolumn{7}{|l|}{ Sex (S): } \\
\hline Ram & .183 & .230 & .072 & $.063^{\mathrm{b}}$ & .029 & .225 \\
\hline Ewe & .187 & .211 & .074 & $.081^{\mathrm{a}}$ & .030 & .257 \\
\hline \multicolumn{7}{|l|}{ Treatment $(\mathrm{T})$ : } \\
\hline Docked & .185 & .231 & .076 & .074 & .029 & .245 \\
\hline Intact & .185 & .210 & .071 & .070 & .030 & .237 \\
\hline SE & .02 & .01 & .005 & .006 & .003 & .02 \\
\hline Interaction $(\mathrm{S} \times \mathrm{T})$ & NS & NS & NS & $\mathrm{p}<.05$ & NS & $\mathrm{p}<.05$ \\
\hline \multicolumn{7}{|l|}{ Sex: } \\
\hline Ram & 23.1 & $29.0^{\mathrm{a}}$ & 9.1 & 8.0 & 3.7 & $27.1^{\mathrm{b}}$ \\
\hline Ewe & 22.0 & $24.8^{\mathrm{b}}$ & 8.8 & 9.5 & 3.5 & $31.4^{\mathrm{a}}$ \\
\hline \multicolumn{7}{|l|}{ Treatment: } \\
\hline Docked & 22.1 & 27.4 & 9.0 & 8.8 & 3.5 & 29.2 \\
\hline Intact & 23.0 & 26.2 & 8.9 & 8.7 & 3.7 & 29.5 \\
\hline
\end{tabular}

${ }^{a, b}$ Values in the same column, within an effect, bearing different superscripts are different $(p<.05)$. 
wholesale cut is a greater in intramuscular fat proportion. Pryor and Warren (1973) stated that differences in muscular activity of different muscle groups produced differences in intramuscular fat formation in the muscles concerned. When the lipid weight in the intramuscular fat component in each cut converted into percentages of total separable lean weight of each corresponding cut, the results revealed that leg and shoulder cuts had the lowest intramuscular fat percentage. This would be expected because of their function in locomotion and the fact that the animal is required to maintain the multiple joints of its limbs to same extent in a state of partial flexion by means of muscular activity (Basmajian, 1967). Hence these muscles are using more energy than the muscles of the trunk. The decreasing order of intramuscular fat content of the trimmed muscles of flank $(11 \%)$, breast $(10.7 \%)$, rack $(10.6 \%)$, loin $(9.9 \%)$, shoulder $(8.8 \%)$ and leg $(6.7 \%)$ cuts is in general agreement in form to that presented by Pryor and Warren (1973).

Least square means for the concentration of lipid in the dissected fat partitions in ram and ewe lambs are presented in table 4. Ewe lambs had a greater $(\mathrm{p}<.05)$ proportion of lipid in the dissected subcutaneous, channel, pericardial, viscera and hide partitions than ram lambs. In a previous study, Thompson et al. (1988) reported a sex effect on the concentration of lipid in dissected fat component, with females having a greater concentration in the subcutaneous depot than males. However, they concluded that sex effect in sheep was confined only to the subcutaneous partition, which coincide with our results. In cattle, Jones et al: (1981) reported that heifers had a greater concentration of lipid in the subcutaneous, intermuscular and body cavity components than bulls. Intact lambs had a greater proportion of lipid in the dissected omental and hide fat component than docked lambs. Generally, within both "sexes" and "docking treatment", the ranking of noncarcass fat partitions on their concentration of lipid was for the greatest concentration in the perirenal, channel or mesentric fat depots and the lowest concentration in the bone component. Within carcass fat partitions, subcutaneous fat followed by intermuscular fat partitions had the highest concentration of lipid.

Least square means for the effect of sex and docking treatment on lipid weight in carcass and noncarcass fat partitions are listed in table 5 . Although total lipid weight in intermuscular and tail fat partitions were different $(\mathrm{p}<.05)$, the total amount of carcass lipid and its components; namely, subcutaneous, intramuscular and bone

TABLE 4. LEAST-SQUARE MEANS AND STANDARD ERRORS (SE) OF THE CONCENTRATION OF LIPID ( $K G / K G$ ) IN EACH OF THE FAT COMPONENT IN THE EMPTY BODIES OF. NADDI LAMBS ADJUSTED TO $40 \mathrm{KG}$ SHORN SHRUNK WEIGHT

\begin{tabular}{|c|c|c|c|c|c|}
\hline \multirow{2}{*}{ Depot } & \multicolumn{2}{|c|}{ Sex } & \multicolumn{2}{|c|}{ Treatment } & \multirow{2}{*}{ SE } \\
\hline & Ram & Ewe & Docked & Intact & \\
\hline Subcutaneous & $.867^{\mathrm{b}}$ & $.904^{\mathrm{a}}$ & .888 & .883 & .011 \\
\hline Intermuscular & .821 & .835 & .820 & .836 & .009 \\
\hline Intramuscular $^{c}$ & .088 & .091 & .089 & .088 & .002 \\
\hline Omental & .857 & .887 & $.850^{\mathrm{b}}$ & $.893^{\mathrm{a}}$ & .019 \\
\hline Mesentric & .882 & .907 & .892 & .897 & .010 \\
\hline Channel & $.879^{\mathrm{b}}$ & $.931^{\mathrm{a}}$ & .897 & .913 & .013 \\
\hline Perirenal & .919 & .929 & .916 & .932 & .007 \\
\hline Pericardial & $.829^{\mathrm{b}}$ & $.900^{\mathrm{a}}$ & .868 & .862 & .011 \\
\hline Tail & .861 & .881 & - & .869 & .034 \\
\hline Viscera & $.095^{\mathrm{b}}$ & $.128^{\mathrm{a}}$ & .116 & .107 & .002 \\
\hline Bone $^{d}$ & .072 & .067 & .074 & .065 & .003 \\
\hline Hide & $.102^{\mathrm{b}}$ & $.154^{\mathrm{a}}$ & $.112^{\mathrm{b}}$ & $.144^{\mathrm{a}}$ & .004 \\
\hline
\end{tabular}

${ }^{a, b}$ Means in the same row, within an effect, bearing different superscripts are different $(p<.05)$.

c Lipid in carcass separable lean.

d Pooled lipid in carcass, feet and head bones. 
TABLE 5. LEAST-SQUARE MEANS AND STANDARD ERRORS (SE) OF LIPID WEIGHT IN VARIOUS FAT COMPONENTS IN THE EMPTY BODY OF NAJDI LAMBS ADJUSTED TO $40 \mathrm{KG}$ SHORN SHRUNK WEIGHT

\begin{tabular}{|c|c|c|c|c|c|c|}
\hline \multirow{2}{*}{ Depot $(\mathrm{kg})$} & \multicolumn{2}{|c|}{ Sex } & \multicolumn{2}{|c|}{ Treatment } & \multirow{2}{*}{$\mathrm{SE}$} & \multirow{2}{*}{ Interaction } \\
\hline & Ram & Ewe & Docked & Intact & & \\
\hline \multicolumn{7}{|l|}{ Carcass: } \\
\hline Subcutaneous & 2.975 & 2.972 & $3.450^{\mathrm{a}}$ & $2.497^{\mathrm{b}}$ & .20 & $\mathrm{p}<.05$ \\
\hline Intermuscular & $1.891^{\mathrm{b}}$ & $2.185^{a}$ & 2.038 & 2.038 & .10 & $\mathrm{p}<.05$ \\
\hline Intramuscular & .802 & .841 & .839 & .804 & .06 & NS \\
\hline Tail & $1.038^{\mathrm{a}}$ & $.826^{\mathrm{b}}$ & - & 1.850 & .11 & $\mathrm{p}<.05$ \\
\hline Carcass bone & .313 & .273 & .318 & .267 & .01 & $\mathrm{p}<.05$ \\
\hline Total carcass & 7.009 & 7.107 & $6.645^{b}$ & $7.456^{\mathrm{a}}$ & .19 & $\mathrm{p}<.05$ \\
\hline \multicolumn{7}{|l|}{ Noncarcass: } \\
\hline Omental & $.551^{\mathrm{b}}$ & $.798^{\mathrm{a}}$ & .706 & .644 & .07 & $\mathrm{p}<.05$ \\
\hline Mesentric & $.864^{\mathrm{b}}$ & $1.361^{\mathrm{a}}$ & 1.124 & 1.102 & .11 & $\mathrm{p}<.05$ \\
\hline Channel & $.160^{\mathrm{b}}$ & $.266^{\mathrm{a}}$ & .232 & .194 & .02 & $\mathrm{p}<.05$ \\
\hline Perirenal & $.379^{\mathrm{b}}$ & $.692^{\mathrm{a}}$ & .527 & .543 & .07 & $\mathrm{p}<.05$ \\
\hline Pericardial & $.090^{\mathrm{b}}$ & $.109^{\mathrm{a}}$ & .102 & .098 & .01 & $\mathrm{p}<.05$ \\
\hline Viscera & $.432^{\mathrm{b}}$ & $.496^{\mathrm{a}}$ & .476 & .452 & .02 & $\mathrm{p}<.05$ \\
\hline Hide & $.285^{\mathrm{b}}$ & $.602^{\mathrm{a}}$ & $.396^{\mathrm{b}}$ & $.491^{\mathrm{a}}$ & .03 & $\mathrm{p}<.05$ \\
\hline Bone $^{c}$ & .128 & .111 & .116 & .124 & .01 & $\mathrm{p}<.05$ \\
\hline Total noncarcass & $2.889^{b}$ & $4.435^{\mathrm{a}}$ & 3.679 & 3.648 & .22 & $\mathrm{p}<.05$ \\
\hline Empty body lipid $(\mathrm{kg})$ & $9.898^{\mathrm{b}}$ & $11.542^{\mathrm{a}}$ & $10.324^{b}$ & $11.104^{\mathrm{a}}$ & .41 & $\mathrm{p}<.05$ \\
\hline Empty body lipid (\%) & $28.6^{\mathrm{b}}$ & $32.8^{\mathrm{a}}$ & 29.7 & 31.6 & 1.84 & $\mathrm{p}<.05$ \\
\hline
\end{tabular}

${ }^{a, b}$ Values in the same row, within an effect, bearing different superscripts are different $(p<.05)$.

${ }^{c}$ Head and feet bones.

partitions, were not affected by sex of lambs. These findings are consistent with the results of Gaili (1978) who found that females had more total intermuscular fat than males, and with those findings by Thompson et al. (1979a) who indicated that total dissectible fat in lamb carcasses was not affected by sex. On the other hand, sex differences in carcass composition, reported by Thompson and Butterfield (1988), have shown that rams have significantly less fat in their carcasses than wethers. Except for lipid weight in bone component, the total noncarcass lipid weight and its components were heavier $(\mathrm{p}<$ $.05)$ in ewe lambs than those of ram lambs, which corroborates previous findings (Dahmen et al., 1985). Generally, the total amount of lipid deposited in the empty body of ewe lambs was heavier $(p<.05)$ in weight than that of ram lambs. This difference reflects the differences in noncarcass lipid weight between ewe and ram lambs. The contribution of carcass and noncarcass lipid to total lipid weight in the empty body differ $(\mathrm{p}<.05)$ between the two sexes. Fat in ram and ewe carcass contributed $70.8 \%$ and $61.6 \%$ of the total lipid in the empty body, respectively. However, the distribution of total lipid weight in the empty body of ram lambs was associated with higher proportions $(p<.05)$ of lipid in the subcutaneous and tail components, and lower proportions $(\mathrm{p}<.05)$ of lipid in the omental, mesentric, perirenal and hide components than in ewe lambs (figure 1).

Despite the fact that the least squares analysis detected few significant effects of docking treaiment on lipid weight in various deports of empty body (table 5), the total lipid weight was heavier $(p<.05)$ in the intact lambs than in the docked ones. This difference was mainly due to the presence of tail fat in the intact lambs. In addition, the greater lipid weight found in hide component of intact lambs probably due to the previous finding (Abouheif et al., 1992) that intact lambs produced heavier pelts than the comparable docked lambs. The docked carcasses 


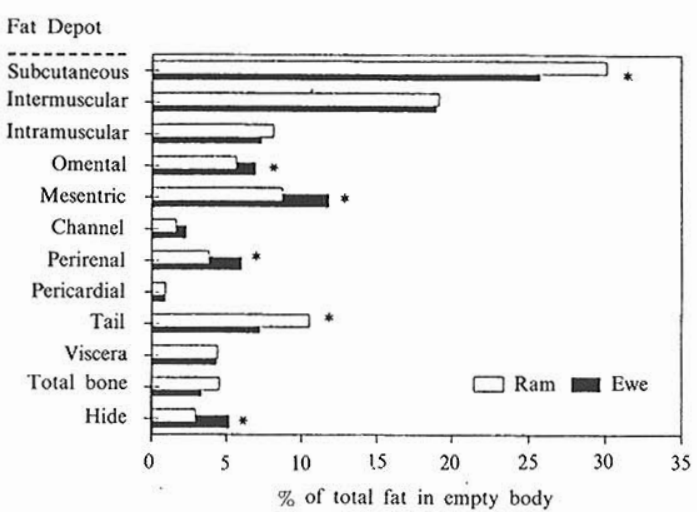

Figure 1. The proportion of lipid in each component relative to the total lipid weight in the empty bodies of ram and ewe lambs.

produced $38.2 \%$ more lipid weight in subcutaneous fat component than the intact carcasses. Therefore, it seems that docking enhanced the fat cells in the subcutaneous depot either by hyperplasia or filling of preexisting cells with storage lipid. A possible interpretation of the results is that, because docked lambs were younger at $40 \mathrm{~kg}$ (Abouheif et al., 1992), they either were more efficient in utilizing available energy or voluntarily consumed greater amounts of energy that was utilized for deposition of subcutaneous fat than did older intact lambs at $40 \mathrm{~kg}$. In a similar connection, several reports concluded that the depot most affected by nutritional manipulation was subcutaneous fat (Little and Sandland, 1975). Furthermore, it can be concluded that, only $57.8 \%$ of the fat that would normally have been stored in the fat tail was distributed in the empty body of docked lambs, where $89 \%$ of this amount was deposited in the subcutaneous depot, mainly in leg and flank cuts. The excess subcutaneous fat produced in docked lambs can be easily trimmed without mutilating the wholesale leg cut. Docking treatment had no effect on the distribution of total lipid weight in the empty body, except for lipid in subcutaneous fat component being greater $(\mathrm{p}<.05)$ in docked lambs than did intact ones (figure 2). Generally, the highest proportion of total lipid distributed in the empty body was associated with subcutaneous depot followed, in order, by intermuscular, mesentric, tail, intramuscular and omental fat depots. Amounts of lipid in subcutaneous fat component was approximately 1.4 times of that of intermuscular fat. These findings are in general agreement with those reported by Russel et al. (1971), Little and Sandland (1975) and Thompson et al. (1979a).

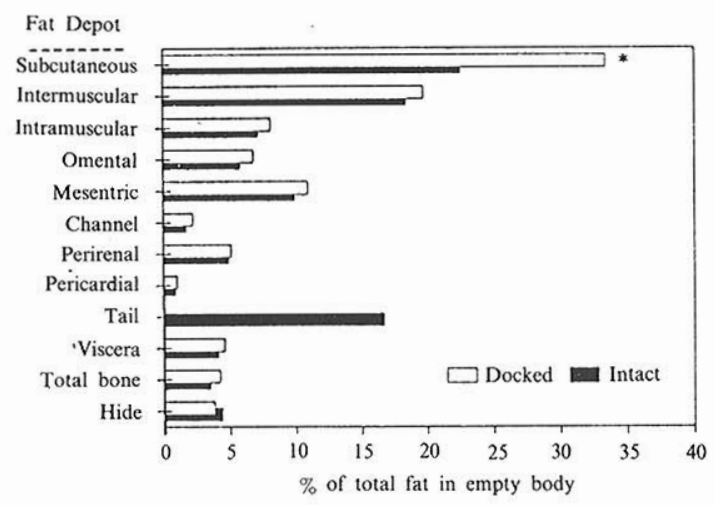

Figure 2. The proportion of lipid in each component relative to the total lipid weight in the empty bodies of docked and intact lambs.

\section{Literature Cited}

Abouheif, M. A., A. A. Alsobayel and S. E. Mostafa. 1988. Distribution of lean, fat and bone in the carcasses of Najdi and Naeimi ram lambs. Arab Gulf J. Sci. Res., Agric. Biolo. Sci. B 6:21-29.

Abouheif, M. A., M. S. Kraidees and R. A. Shatat. 1992. Effects of docking and sex of lambs on carcass characteristics of fat-tailed Najdi sheep. J. Appl. Anim. Res. 1:91-101.

Basmajian, J. V. 1967. Muscles Alive. Their Functions Revealed by Electromyography. pp. 148, 2nd Ed., Baltimore:William and Wilkins, USA.

Dahmen, J. J., J. A. Jacobs and E. J. Morrison. 1985. Suffolk versus Lincoln rams: The influence of sire and breed cross on carcass traits of heavy market lambs. J. Anim. Sci. 61:98-106.

Field, R. A., J. J. Bass, A. H. Kirton and P. J. Fowke. 1985. Distribution of ether extract, moisture, protein and ash in dissected tissues from ovine carcasses. J. Anim. Sci. 60:977-988.

Gaili, E. S. E. 1978. A note on the effect of breed-type and sex on the distribution of intermuscular fat in carcasses of sheep. Anim. Prod. 26:217-219.

Jones, S. D. M., M. A. Price and R. T. Berg. 1981. Accumulation of lipid in rib cuts from bull and heifer carcasses of two breeds. Canadian J. Anim. Sci. 61:23-726.

Kempster, A. J., P. R. D. Avis and R. J. Smith. 1976. Fat distribution in steer carcasses of different breeds and crosses. 2- distribution between joints. 


\section{ABOUHEIF ET AL.}

Anim. Prod. 23:223-232.

Kempster, A. J. 1981. Fat partition and distribution in the carcasses of cattle, sheep and pigs: A review. Meat Sci. 5:83-98.

Leymaster, K. A. and T. G. Jenkins. 1985. Age effects on the chemical composition of male Suffolk sheep at 32 and $73 \mathrm{~kg}$ of live weight. J. Anim. Sci. 61: 423-429.

Little, D. A. and R. L. Sandland. 1975. Studies on the distribution of the body fat in sheep during continuous growth, and following nutritional restriction and rehabilitation. Aust. J. Agric. Res. 26:363-374.

Pryor, W. J. and G. H. Warren. 1973. Chemical fat in the musculature of the sheep carcass. J. Agric. Sci., Camb. 80:219-224.

Romans, J. R., K. W. Jones, W. J. Costello, C. W. Carlson and P. T. Ziegler. 1985. The Meat We Eat, The interstate printers \& Publishers. Inc. USA. pp. 161-176.

Russel, A. J. F., J. M. Doney and R. G. Gunn. 1971. The distribution of chemical fat in the bodies of Scottish Blackface ewes. Anim. Prod. 13:503-509.

SAS. 1986. SAS User's Guide: Statistics. SAS Inst. Inc., Carry, NC, USA.
Theriez, M., M. Tissier and J. Robelin. 1981. The chemical composition of the intensively fed lamb. Anim. Prod. 32:29-37.

Thompson, J. M., K. D. Atkins and A. R. Gilmour. 1979a. Carcass characteristics of heavy weight crossbred lambs. II. Carcass composition and partitioning of fat. Aust. J. Agri. Res. 30:12071214.

Thompson, J. M., K. D. Atkins and A. R. Gilmour. 1979b. Carcass characteristics of heavy weight crossbred lambs. III. Distribution of subcutaneous fat, intermuscular fat, muscle and bone in the carcass. Aust. J. Agric. Res. 30:1215-1221.

Thompson, J. M. and R. M. Butterfield. 1988. Changes in body composition relative to weight and maturity of Australian Dorset Horn rams and wethers. 4. Adipocyte volume and number in dissected fat partitions. Anim. Prod. 46:387-393.

Thompson, J. M., R. M. Butterfield and K. J. Reddacliff. 1988. Food intake, growth and body composition in Australian Merino sheep selected for high and low weaning weight. 5. Adipocyte volume and number in the dissected fat partitions. Anim. Prod. 46:395-402. 